\title{
A study of pregnancy related acute kidney injury and its outcome at a tertiary care centre, civil hospital, Ahmadabad, Gujarat, India
}

\author{
Komal K. Agrawal*, Mahima Jain
}

Department of Obstetrics and Gynecology, B. J. Medical College, Civil Hospital, Ahmedabad, Gujarat, India

Received: 10 July 2019

Accepted: 30 August 2019

\section{*Correspondence:}

Dr. Komal K. Agrawal,

E-mail: anne.komal@gmail.com

Copyright: () the author(s), publisher and licensee Medip Academy. This is an open-access article distributed under the terms of the Creative Commons Attribution Non-Commercial License, which permits unrestricted non-commercial use, distribution, and reproduction in any medium, provided the original work is properly cited.

\begin{abstract}
Background: Pregnancy related acute kidney injury (PRAKI) is acute kidney injury occurring during pregnancy, labour, delivery, and/or postpartum period. Proper management of PRAKI is challenging because (i) both maternal and fetal health must be considered and (ii) the cardiovascular and renal adaptations of pregnancy add to the complexity of diagnosis and management. A multi discipilinary team is often needed to optimize all aspects of the pregnant women's care.

Methods: To study association and contributing factors in pregnancy related Acute Kidney injury, a retrospective study of 39 cases of acute kidney injury complicating pregnancies was carried out in department of obstetrics and gynaecology, B. J. Medical college over a period of 6 months, and results were studied and analysed. Etiologicalfactors, associated liver pathology, coagulation abnormality, thrombocytopenia, sepsis, recovery status and fetomaternal outcome were studied and results were tabulated. AKI was analysed in terms of maximal stage of renal injury attained as per risk, injury, failure, loss of function, and end-stage renal disease (RIFLE) criteria.

Results: The incidence of ARF in pregnancy was found to be $0.3 \%$. Hypertension and its related complications were the most common causative factor. $59.5 \%$ of cases required hemodialysis and except for 6 cases $(14.3 \%)$ all had complete or at least partial recovery from failure.

Conclusions: AKI complicating pregnancies are not uncommon in tertiary care centres. If recognized and treated promptly, recovery is assured in majority of $85.7 \%$ of cases. Early identification and prompt management of preeclampsia and sepsis can prevent majority of ARF cases.
\end{abstract}

Keywords: Abortion, Feto maternal outcome, Hypertension, Kidney injury, Pregnancy, Recovery

\section{INTRODUCTION}

Acute kidney injury is a syndrome characterized by the rapid loss of kidney's excretory function and is typically diagnosed by accumulation of end products of nitrogen metabolism (urea and creatinine) or decreased urine output or both i.e. increase in serum creatinine by 0.3 $\mathrm{mg} / \mathrm{dl}(26.5 \mu \mathrm{mol} / \mathrm{l})$ within 48 hours or increase in serum creatinine to 1.5 times baseline, which is known or presumed to have occurred within the prior 7 days; or urine volume of $<0.5 \mathrm{ml} / \mathrm{kg} /$ hour for 6 hours. ${ }^{1}$ The renal changes may be only temporary, and resolve within a few weeks postpartum, or may become irreversible leading to a progression of chronic kidney disease(CKD). ${ }^{2,3}$

Pre-eclampsia/ eclampsia is the most common cause of AKI during pregnancy and purperium, however, the outcome of pre-eclampsia related AKI is good. Amniotic fluid embolism and postpartum hemorrhage are the leading causes of maternal mortality. ${ }^{4,5}$ 
The incidence of AKI in pregnancy declined significantly over the second half of the $20^{\text {th }}$ century in industrialized countries, but is still a significant cause of maternal morbidity and mortality in developing countries. It currently affects 1 per 20,000 pregnancies. ${ }^{6,7}$ Hence, it is essential to focus on the prevention, periodic evaluation of pregnant women and improvement in the care during the peripartum period to improve maternal and perinatal outcomes. Due to advances in contraception, legalizing abortion and more careful monitoring of the perinatal period, the incidence of PRAKI is on decreasing trend. ${ }^{8-10}$

The maternal condition after active treatment was good, whereas the pregnancy outcomes were generally poor. ${ }^{11,12}$

\section{METHODS}

Retrospective observational study conducted in the department of obstetrics and gynaecology, B. J. Medical College, Ahmedabad, Gujarat, India form October 2017 to March 2018 (6 months). Total 39 cases were studied and analysed.

Data collected from cases were analysed, computed and tabulated according to standard performa.

\section{Inclusion criteria}

- Sudden oliguria 24 hours UOP $<400 \mathrm{ml}$

- Anuria

- $\quad$ Sr. Creatinine $>1.5 \mathrm{mg} / \mathrm{dl}$.

\section{Exclusion criteria}

- Already known cases of chronic kidney diseases.

The etiological factors, associated liver pathology, coagulation abnormality, thrombocytopenia, sepsis, recovery status and fetomaternal outcome were studied and results were tabulated.

\section{RESULTS}

In present study, total 39 patients were studied. As shown in Table 1, pregnancy related acute kidney injury was most common in patients with pre-eclampsia, eclampsia and HELLP syndrome. About $62 \%$ of PRAKI cases were due to hypertension related complications in pregnancy. Next most common being septicemia accounting for about $24 \%$ of cases.

\section{Table 1: Etiological factors of PRAKI in pregnant} study.

\begin{tabular}{|lll|}
\hline Etiological factor & $\mathrm{N}=39$ & $\%$ \\
\hline Preeclampsia/ Eclampsia/ HELLP & 24 & 61.9 \\
\hline Abruption & 2 & 4.7 \\
\hline Septicemia & 9 & 23.8 \\
\hline Haemorrhage (APH+PPH) & 4 & 9.5 \\
\hline
\end{tabular}

As described in Table 2, pregnancy related acute kidney injury was more common in patients with age $>35$ years as chances of hypertension related complications increase with increasing maternal age and pregnancy related hypertensive disorders being the commonest etiological factor of PRAKI.

Table 2: Relationship between maternal age and PRAKI.

\begin{tabular}{|lll|}
\hline Age & $\mathbf{N}=39$ & $\%$ \\
\hline$<35$ & 13 & 33.3 \\
\hline$>35$ & 26 & 66.7 \\
\hline
\end{tabular}

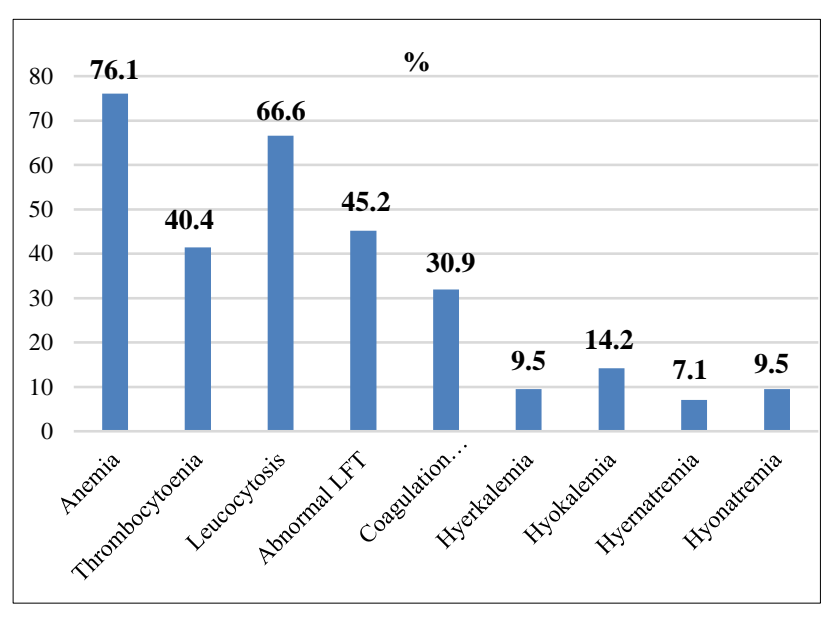

Figure 1: PRAKI and associated laboratory abnormalities.

As shown in following Figure 1, pregnancy related acute kidney injury usually is associated with various laboratory abnormalities and majority of the patient had more than 1 abnormality. Anaemia, leucocytosis and abnormal liver function test were present in about twothird of cases. Hypertension related complications are frequently associated with abnormal liver function tests and also leucocytosis is a common laboratory abnormality in such patients. Electrolyte abnormalities were relatively less common.

Table 3: Renal recovery in patients with acute kidney injury.

\begin{tabular}{|lll|}
\hline Recovery & $\mathbf{N}=39$ & $\%$ \\
\hline Complete & 32 & 81 \\
\hline Partial & 2 & 4.8 \\
\hline Death & 5 & 14.3 \\
\hline
\end{tabular}

Results mentioned in Table 3 show that, complete renal recovery was seen in $32(81 \%)$ cases, partial recovery in $2(4.8 \%)$ cases and maternal death occurred in $5(14.3 \%)$ cases. From 5 cases of maternal death, all cases were referred case, diagnosed during intrapartum and postpartum period. Admission to delivery time was 3 to 12 hours in cases of maternal death. 3 cases delivered vaginally and other 2 cases delivered by cesarean section. 
Out of 5 one case had severe and other 4 cases had moderate severity of renal failure.

Table 4: Maternal and fetal outcome in patients with PRAKI.

\begin{tabular}{|llll|}
\hline Maternal or fetal & Outcome & N=39 & $\%$ \\
\hline \multirow{2}{*}{ Maternal } & Recovery & 34 & 85.7 \\
\cline { 2 - 4 } & Death & 5 & 14.3 \\
\hline \multirow{2}{*}{ Fetal } & Stillbirth/IUD & 28 & 71.4 \\
\cline { 2 - 4 } & Live & 11 & 28.6 \\
\hline
\end{tabular}

Table 4 shows that, $85.7 \%$ of cases had recovery and maternal death occurred in 5 cases. PRAKI was associated with poor fetal outcome. Only 11 out of 39 had live birth, rest 12 were stillbirth and 16 were intrauterine death.

Table 5: In comparison to Huang $\mathrm{C}$ et al, study and Rao $\mathrm{S}$ et al, study in terms of recovery and commonest cause. $^{13,14}$

\begin{tabular}{|llll|}
\hline & $\begin{array}{l}\text { Huang C } \\
\text { et al, }\end{array}$ & $\begin{array}{l}\text { Rao S } \\
\text { et al, }\end{array}$ & $\begin{array}{l}\text { Present } \\
\text { study }\end{array}$ \\
\hline Incidence (\%) & $0.81 \%$ & $0.45 \%$ & $0.31 \%$ \\
\hline Most common cause & PIH & PIH & PIH \\
\hline Recovery (\%) & $94 \%$ & $93 \%$ & $85.7 \%$ \\
\hline
\end{tabular}

As we can see in Table 5, comparing present study with other studies relating to acute kidney injury in pregnancy, gave similar results. Incidence of PRAKI has reduced in developed countries but is still a significant cause of maternal morbidity and mortality in developing countries. Hypertensive disorders of pregnancy (pre-eclampsia, eclampsia and HELLP syndrome) are the commonest causes of PRAKI. Though maternal outcomes are good, intensive management is required for good recovery rates. PRAKI due to hypertensive disorders usually have better outcomes than those occurring secondary to haemorrhage or septicaemia.

\section{DISCUSSION}

$\mathrm{ARF}$ is an infrequent but life threatening complication. Though PRAKI accounts for $17-43 \%$ of total ARF cases, the worldwide incidence of pregnancy-related acute kidney injury (PRAKI) has decreased in developed countries through legalization of abortion and improvement of antenatal and obstetric care. ${ }^{15}$ In the recent years, the incidence of PRAKI in developed countries is only 1 to $2.8 \%$. However, PRAKI is still frequent in developing countries and the incidence is around $4.2-15 \%{ }^{16}$

Hypertension and its related complications were most common causes of PRAKI in present study followed by sepsis. Incidence is more in females of age $>35$ years of age. This is due to increased risk of hypertensive complications with increasing age. Though maternal outcome is good if early diagnosis and prompt management is done but neonatal outcome is usually poor in pregnancies associated with acute kidney injury. Also, PRAKI is associated with number of laboratory abnormalities and majority of patients have more than one laboratory abnormalities requiring intensive management. Prevention, early recognition and prompt treatment are ideal. Avoiding nephrotoxic drugs, ensuring volume status/perfusion pressure, functional haemodynamic monitoring and monitoring of serum creatinine and urine output is must. ${ }^{17}$

The reported mortality rate of PRAKI in present study was 5/39 (14.3\%). Comparing results with other studies, similar outcome was obtained. Huang $\mathrm{C}$ et al study on pregnancy related acute kidney injury at china had similar results showing decreasing incidence of PRAKI in developed countries but still a matter of concern for developing countries, hypertensive disorders being the commonest cause of PRAKI, poor neonatal outcomes and intensive management required for good recovery rates. As shown above, similar were the results obtained from Rao $\mathrm{S}$ et al study.

\section{CONCLUSION}

AKI complicating pregnancies are not uncommon in tertiary care centres. If recognized and treated promptly, recovery is assured in majority of cases $(85.7 \%)$. Early identification and prompt management of pre-eclampsia and sepsis can prevent majority of ARF cases. Prolonged duration of oliguria and antepartum haemorrhage were strong predictors of poor renal outcome and irreversible renal failure. Multidisciplinary care is required for PRAKI including obstetrician /ICU /nephrologist /neonatologist.

Funding: No funding sources

Conflict of interest: None declared

Ethical approval: Not required

\section{REFERENCES}

1. Nwoko R, Plecas D, Garovic VD. Acute kidney injury in the pregnant patient. Clin Nephrol. 2014;78:478-86.

2. Filipowicz E, Staszków M. Pregnancy-related acute kidney injury. Wiad Lek. 2016;69(5):721-4.

3. Prakash J, Prakash J, Niwas SS, Parekh A, Pandey LK, Sharatchandra L, et al. Acute kidney injury in late pregnancy in developing countries. Renal failure. 2010;32(3):309-13.

4. Goplani KR, Shah PR, Gera DN, Gumber M, Dabhi, M, Feroz A, et al. Pregnancy related acute renal failure: a single-center experience. Indian J Nephrol. 2016; 18:17-21

5. ACOG practice bulletin. Diagnosis and management of preeclampsia and eclampsia. Number 33, January 2018. ACOG Committee on Practice BulletinsObstetrics, Obstet Gynecol. 2002;99(1):159. 
6. Huang C, Chen S. Acute kidney injury during pregnancy and puerperium: a retrospective study in a single center. BMC Nephrol. 2017;18(1):146.

7. Mahajan S, Tiwari S, Bhowmik D, Agarwal SK, Tiwari SC, Dash SC. Factors affecting the outcome of acute renal failure among the elderly population in India: a hospital based study. Int Urol Nephrol. 2006;38(2):391-6.

8. Prakash J, Ganiger VC. Acute kidney injury in pregnancy-specific disorders. Indian $\mathbf{J}$ Nephrol. 2017:27(4):258.

9. Najar MS, Shah AR, Wani IA, Reshi AR, Banday KA, Bhat MA, et al. Pregnancy related acute kidney injury: a single center experience from the Kashmir Valley. Indian J Nephrol. 2008;18(4):159.

10. Prakash J, Pant P, Prakash S, Sivasankar M, Vohra $\mathrm{R}$, Doley PK, et al. Changing picture of acute kidney injury in pregnancy: Study of 259 cases over a period of 33 years. Ind J Nephrol. 2016 Jul;26(4):262-7.

11. Liu Y, Y, Bao H, Jiang Z, Huang Y, Wang N. Pregnancy-related Acute Kidney Injury and a Review of the Literature in China. Intern Med. 2015;54(14):1695-703.

12. Huang Y, Wang N. Pregnancy related acute kidney injury and a review of literature in china. 2016;23(4):502.

13. Huang C. Study of pregnancy related acute kidney injury at china in 2017. Available at: https://bmcnephrol.biomedcentral.com/articles/10.11 86/s12882-017-0551-4.

14. Rao S. Acute kidney injury in pregnancy: the changing landscape for the $21^{\text {st }}$ century. https://www.ncbi.nlm.nih.gov/pmc/articles/PMC593 2309/.

15. Arrayhani M, El Youbi R, Sqalli T. Pregnancyrelated acute kidney injury: experience of the nephrology unit at the university hospital of fez, morocco. ISRN Nephrol. 2012;2013.

16. Godara SM, Kute VB, Goplani KR, Gumber MR, Gera DN, Shah PR, et al. Mucormycosis in renal transplant recipients: predictors and outcome. Saudi J Kid Dis Transplant. 2011;22(4):751.

17. Godara SM, Kute VB, Trivedi HL, Vanikar AV, Shah PR, Gumber MR, et al. Clinical profile and outcome of acute kidney injury related to pregnancy in developing countries: a single-center study from India. Saudi J Kid Dis Transplant. 2014;25(4):906.

Cite this article as: Agrawal KK, Jain M. A study of pregnancy related acute kidney injury and its outcome at a tertiary care centre, civil hospital, Ahmadabad, Gujarat, India. Int J Reprod Contracept Obstet Gynecol 2019;8:4020-3. 